\title{
Men in breast cancer families: a preliminary qualitative study of awareness and experience
}

\author{
Marion F McAllister, D Gareth R Evans, Wilma Ormiston, Peter Daly
}

\begin{abstract}
In inherited forms of breast cancer, attention in clinical genetics services has focused on women because they are most at risk of developing cancer. Men at risk of transmitting a predisposing gene mutation are less likely to have a genetic test than the women in these families. This preliminary study investigates the perspective of the brothers of women with familial breast cancer and is based on qualitative analysis of 22 semistructured interviews using an attenuated form of Grounded Theory. There is an awareness among these men (without having had genetic counselling) that the breast cancer in their families is inherited. Some of them harbour fear of developing cancer themselves and many are concerned that their daughters might develop breast cancer. Some appeared to use avoidance as a coping strategy. The men were very often excluded from family conversations about breast cancer. Implications for the provision of genetic counselling for these families are discussed.

$(F$ Med Genet 1998;35:739-744)
\end{abstract}

Keywords: familial breast cancer; men; awareness; family communication

A family history of breast cancer, particularly where there is a younger age at onset or bilaterality or both, may indicate an inherited predisposition. ${ }^{1}$ In $4 \%$ of cases of breast cancer, and up to $25 \%$ of cases diagnosed before the age of 50 , the condition can be attributable to a dominantly inherited susceptibility. ${ }^{2}{ }^{3}$ Two genes (BRCA1 and BRCA2) have been identified in which mutations confer a lifetime risk of up to $87 \%$ of developing breast cancer, ${ }^{34}$ and some clinics have begun to offer predictive genetic testing for BRCA1. ${ }^{56}$

Attention in genetics clinics has focused on the women in these families because they are most at risk of developing cancer. In these families, men are less likely to take up an offer of a predictive genetic test. ${ }^{56}$ In addition, it is clear from the profile of patients attending genetics clinics that women at risk because of a paternal family history of breast cancer are under-represented. ${ }^{7}$ Possible causes of these trends might include (1) referral practices of GPs, or (2) an assumption in such families that risk cannot be transmitted by males since breast cancer affects (for the most part) females only, or (3) a less positive attitude among men towards addressing health issues in general and attending for genetic counselling or testing specifically. A recent study of four men from breast cancer families enrolled in a predictive genetic testing programme has indicated that men in these families experience some difficulties with the genetic counselling process. They exhibit avoidance and have a tendency to miss appointments and drop out of the testing protocol. ${ }^{8}$

The aim of this paper is to describe the attitudes and experiences of men in these families in an attempt to gain further understanding of family processes surrounding a family history of breast cancer. We describe a preliminary study of 22 men in breast cancer families. The questions investigated are: (1) Are the men in these families aware that the disease may be inherited? (2) Do they think that they are at risk of cancer themselves? (3) Do they think their daughters are at risk? (4) How do the families communicate about breast cancer? (5) How do the men cope with the breast cancer in the family?

The approach taken to this work is qualitative. The study is a preliminary attempt to obtain insight into the perspective of a group of men from breast cancer families using an attenuated form of Grounded Theory Approach derived from Glaser and Strauss ${ }^{9}$ by Pidgeon et al. ${ }^{1011}$ This is part of continuing research on gender issues in cancer families.

\section{Methods}

SUBJECTS

Over the past eight years, a hospital oncology clinic in Ireland has identified a number of families with a strong family history of breast cancer. A set of criteria were designed (table 1) to identify men whose existing or potential daughters would have a lifetime risk of developing breast cancer of at least 1 in $5 .^{12} 13$ Forty-two men who met these criteria were identified from 16 families. The breast cancer patients in these families had all been informed of the possible inherited nature of their disease as part of their routine oncology reviews. Genetic counselling services in Ireland are very limited and there are no formal cancer family clinics.

\section{RESPONSE BIAS}

Twenty-two of the 42 men identified agreed to be interviewed. More men with daughters participated in the study than men without daughters. Table 2 examines this response bias. Unfortunately, we have no further information about non-participants. 
Table 1 Inclusion criteria

Basic criteria:

And the index case has at least one of the following
(1) Breast cancer diagnosed in index case before age 50

(2) Index case has at least one brother aged between 25 and 60

Bilateral breast cancer

One first degree relative with breast cancer diagnosed before age 50

One second degree relative with breast cancer either diagnosed before age 50

or the intervening relative is either male or died young from another cause

One first degree relative with ovarian cancer
SAMPLE CHARACTERISTICS

All participants were Irish males aged between 25 and 60 years; $77 \%$ of participants were married, $63 \%$ had children, and $54 \%$ had daughters (table 1). No participant was divorced, separated, or cohabiting. None of the participants had received any genetic counselling regarding their sister's breast cancer.

\section{PROCEDURE}

All the men were contacted with the previous permission of the index case. Neither "genetics" nor "family history" were mentioned directly by the researcher in any contact with the family until the interview was over. The men were asked if they were willing to discuss their experience of their sister's disease. Participants were interviewed in person in their homes. The interview took the form of a semistructured discussion around the following themes: possible causes of sister's breast cancer; concerns about own and (potential) children's health; family communication; reaction to the breast cancer in the family.

Interviews were taped and transcribed with consent and analysed using an attenuated form of Grounded Theory Approach. Grounded Theory $^{911}$ is a means of generating theory "bottom-up" from unstructured or semistructured material, in which emerging categories are defined and redefined using the method of constant comparison. The approach used in this work was derived from Glaser and Strauss ${ }^{9}$ by Pidgeon et al. ${ }^{10}$

\section{Results}

ARE THE MEN IN THESE FAMILIES AWARE THAT THE DISEASE MAY BE INHERITED?

Twelve interviewees (55\%) were classified as "easily able to identify" inheritance factors as they used one of these words or phrases in relation to the breast cancer in their family in response to an open question "What do you think might have caused or contributed to your sister's breast cancer?": "a gene", "genetic", "hereditary", "inherited", "it runs in the family".

These phrases were open coded as "Awareness" according to the principles of Grounded Theory ${ }^{11}$ and thus were not codes preconceived

Table 2 Response bias

\begin{tabular}{llllll}
\hline & \multicolumn{3}{l}{ Agreed to be interviewed? } \\
\cline { 2 - 3 } & \multicolumn{2}{l}{ Yes } & & No \\
\cline { 2 - 3 } \cline { 5 - 6 } Characteristic & No & $\%$ & & No & $\%$ \\
\hline Married & 17 & 77 & & 9 & 45 \\
Children & 14 & 63 & & 8 & 40 \\
Daughters & 12 & 54 & & 5 & 25 \\
Total & 22 & 100 & & 20 & 100 \\
\hline
\end{tabular}

before data analysis. A further four men (18\%) were classified as "having difficulty identifying" inheritance factors, as they did not mention inheritance factors in response to this question, but mentioned inheritance factors elsewhere in the interview. Six men (27\%) identified environmental factors only as causing their sister's breast cancer, for example, smoking.

Those who did mention inheritance factors spontaneously in the interview seldom said this directly. Verbal deliberation occurred as the men attempted to work out the cause by assessing the evidence available to them, that is, the presence or absence of known environmental causes of cancer. It seemed that only if environmental factors could not account, to their own satisfaction, for the cancers in the family did they conclude that it must be inherited.

"[My sisters] never worked any place where there'd be asbestos or anything...to my knowledge now they didn't come into contact with anything like that...obviously it must have been a gene...something triggered it somewhere along the line...obviously the two older girls [who didn't have breast cancer] weren't carrying the gene..."

"I don't know. She never smoked, drank very moderately...good woman...four or five kids... unless it's genetic, that's the only thing I can come up with, I mean there was no social misbehaviour...she just got it."

None of the men attributed his sister's breast cancer solely to inheritance. If inherited causes were identified, many subjects also postulated other possible causes and appeared to have no difficulty maintaining a multifactorial model.

"My sister smoked heavily as a teenager...she never drank...it could have been diet...she ate a lot of rubbish food, over-boiled vegetables and the like..."

There was evidence that eight men had been specifically told about the possible inherited basis for their sister's breast cancer, either by their sister or by a doctor. However, many seemed to have come to the conclusion themselves. There was no obvious connection between having been told about the possible inherited contribution and volunteering this information in response to this question. The pattern that appeared to emerge was one of resistance to explanations that were not a result of their own rational conclusions. Four of the eight men who described having been told, interestingly, did not mentioned inheritance in their explanation of causes.

"According to what [my sisters] would be saying...they seem always to be the ones that know everything about it, apparently someone has told them it's in the genes...I don't know whether it is or not..." 
DO THE MEN THINK THEY ARE AT RISK OF CANCER THEMSELVES?

When asked "Do you have any concerns about your own health?", 12 of the men reported having gone through a period of harbouring great fear of cancer. For some, this period came shortly after the first diagnosis of breast cancer in their family and was later put behind them, but for others the fear casts a constant shadow on their lives.

"Paranoia sets in...you think 'it could happen to me'...you feel very vulnerable, watching every lump and bump..."

"At one point I seriously thought I had some kind of cancer...I was working out in the gym and the shorts I was wearing...I got an awful pain in one of my testicles...I thought 'This is it - cancer'...it was just that the shorts were too tight!"

Two men expressed fear of developing breast cancer themselves.

"Men don't get breast cancer, do they?...I hurt my chest one time...my nipple was sore...started thinking...I was just reading that a while ago...in one of the magazines my wife gets...actually showed a man...very rare..."

"The worry would always be there...I get lumps around my nipple sometimes...the doctor says it's nothing, maybe muscle tension."

None of the men admitted having any concerns about their health other than in relation to cancer. Some of the men used inheritance of other characteristics, often following a gender specific pattern, to explain that they did not consider themselves at risk.

"I'm much more like my dad's side...they all live real long..."

"My father's never been sick and I take after him."

\section{DO THE MEN THINK THEIR DAUGHTERS ARE AT} RISK?

Awareness of the risk of transmission to daughters was indicated if the men admitted concern about any increased risk their (potential) daughters might have of developing breast cancer in view of the family history in response to the open question: "Do you have any concerns about your children's health?" Nine of the 12 subjects aware of the inherited nature of breast cancer in their family also admitted some concerns that their (potential) daughters might develop breast cancer.

"I would imagine my daughter might get it on account of the family history."

“...It's always a possibility with the history of the three girls...higher possibility than the woman next door."

"I do think the 3 year old, is she going to get it in 30 or 40 years time?"

None of the men mentioned having any specific concerns for their (potential) sons' health, although one man who had both sons and daughters was worried about the risk of meningitis for his children of both sexes. As part of the Grounded Theory analysis, a hypothetical link emerged indicating that men with adult daughters may have more difficulty identifying a possible genetic component to their sister's cancer than men with younger daughters or men without daughters.

\section{HOW DO THE FAMILIES COMMUNICATE ABOUT} BREAST CANCER?

Communication about breast cancer in these families occurs almost exclusively between women. With one exception, all the men reported being excluded from family conversations about their sisters' breast cancer.

"I've heard them [his sisters] talking about it among themselves...never actually talked to me about it...I know they talk about it when they're all here together, you'd hear them, but they never actually talked to me."

"The girls never actually tell us stuff like that."

Furthermore, some men appeared to collude with this situation by actively avoiding discussions about breast cancer.

"My attitude was 'Just stay out of it'."

“... For some reason...I don't know why...maybe it's that there's a stigma attached to it... but it's something that they would never discuss with me and I would never ask."

In fact, every overt aspect of the management of the disease appears to be the sole preserve of women in these families. The women in the families tend to be much more involved with the breast cancer patients than the men. The women seem to rally around what is considered to be a "girl's problem". A brother's wife is often more likely to be involved with his sister than the brother himself.

"To be honest, she [sister without breast cancer] does an awful lot more for [sister with breast cancer] than me..."

"It was a girl's problem..."

"I work...my wife, she'll go down maybe once a week and spend some time with [my sister]."

HOW DO THE MEN COPE WITH THE DISEASE IN THE FAMILY?

No attempt was made here to measure coping. However, during the interviews, many of the men provided an insight into the manner in which they think about the breast cancer in their families. Following the initial shock of diagnosis, the men in these families tend not to focus or dwell on the problem. They prefer to avoid thinking about it.

"I just wanted to forget about it and get on with what we had to do."

"Maybe it's just the way I have of looking at things. As soon as anything like that comes into my head, I just put it out."

"I never dwell on it."

The position taken by some of the men with regard to the possible causes of the breast cancer in their families could also be interpreted as suggestive of avoidance in the face of a very strong family history.

"I have no speculations as to why, or why one and not the other, if someone can give me a definite answer, then great...idle speculation is not for me."

"I didn't say it's hereditary...I didn't actually say it was...all I said was you actually start to 
think 'Is it hereditary...is it something that comes down in the genes'?"

"I don't question so much how they got ill, as how soon will they be better."

Some of the men seemed unable to come out and state the possible genetic contribution to their sister's breast cancer, preferring to leave the words unsaid, or implied, as if it were painful to articulate.

"All my grandchildren at the minute are girls as well...so I worry, you know, if it's...if it's...if there is..."

"I think she probably regularly had [discussions about the cause of her cancer] but I suspect she would have come up with the same conclusion as I did...could have been anything...but there's something staring you in the face that probably heads the posse somewhat..."

"Well, what would you think? If your mother and father had it, and your two sisters? What would you think?"

The use of avoidance strategies among these men was evident to some degree in all the interviews, and it was clear that the exclusion of the men from family conversations about breast cancer made this an easy route for the men to take. It was also clear from one case where a brother had been closely involved with his sister's illness (because, apparently, there was no woman in the family to take this role) that close involvement was particularly distressing for this man.

"She had the chemo and all...I used to bring her there...she lost all her hair and did all the things and she stayed with me...it brought about a lot of changes in me, personally...I hit the bottle a fair bit...I couldn't cope with it for years, I'd just go on the piss...I can't say why...but it took me an awful long time to get over it, the fact of watching her dying..."

\section{Discussion}

THEORETICAL PROPOSITIONS

This is a preliminary Grounded Theory study, the aim being to produce a set of theoretical propositions grounded in the data. These propositions are set out below. Development of this preliminary study will involve gathering more data using the principles of Theoretical Sampling in order to enrich and tightly integrate the theory; following this, the theory would be ready for testing using traditional quantitative methods.

\section{Proposition 1}

Many men in families with a symptomatic family history of breast cancer are aware that the breast cancer in their family might be inherited.

The results presented here on a small sample of men from breast cancer families has indicated that many of the men are aware at some level that the breast cancer in their families might be inherited. The way they answered the question about causes of their sister's breast cancer indicated that these men had recognised a genetic component, having realised at some level that environmental factors could not explain to their own satisfaction the high incidence of breast cancer in their female rela- tives. Further studies will be required to investigate this before firmer generalisations can be made. These men's awareness does not seem to have been substantially influenced by having been told by anyone else that the condition in the family might be inherited. Data concerning educational level were not collected; this may well influence awareness about inheritance and would be useful data to gather in a follow up study. It appears that the men in this study have rationalised the situation by drawing on two sets of beliefs, firstly in relation to what they know about the causes of cancer in general, and, secondly their beliefs about how physical characteristics can run in families, for example, following a gender specific pattern. ${ }^{14} 15$ They have concluded that the only explanation that could satisfy them was that the disease "runs in the family", that the women are most at risk of developing breast cancer, and that environmental factors have some important part to play.

\section{Proposition 2}

Men with a symptomatic family history of breast cancer are often concerned about developing cancer themselves.

Many of the men in these families expressed concern about developing breast cancer or other forms of cancer themselves. Some harbour fears of developing cancer of their own sexual organs. It is not completely clear from this study whether this is a result of heightened awareness about cancer because others in the family have had cancer, or whether they think that they are at higher risk as a result of their family history.

\section{Proposition 3}

Men with a symptomatic family history of breast cancer tend to suspect that their existing or potential daughters might be at risk.

Many of the men thought that their daughters or potential daughters were at higher risk of developing breast cancer because of the family history. A hypothesis emerged from the data suggesting that men with adult daughters may have more difficulty identifying their daughters' risk status. This may be an artefact of the small sample size and the limited context in which participants were ascertained, or it may be suggestive of denial or denial-like processes (in relation to their possible carrier status) setting in once daughters become fully grown women and enter the high risk period. This would form a suitable issue for investigation by further data collection, as a number of plausible contextual influences might be at work here, for example, better education about genetics among younger fathers, or better education among younger school children having an influence over their father's understanding of genetics.

\section{Proposition 4}

Men with a symptomatic family history of breast cancer tend to use avoidance as a coping strategy.

Avoidance was very often seen in these interviews as the men described how they think 
about the family history of breast cancer. It will be important in further studies to establish the prevalence of avoidance as a coping strategy used by men in breast cancer families because it may throw some light upon the underrepresentation of men in predictive testing protocols, ${ }^{56}$ and possibly also the underrepresentation in genetics clinics of women at risk of familial breast cancer through paternal transmission. It is also of some theoretical interest to uncover any relation between avoidance and gender, as this may inform how clinical and counselling services are offered to men and women.

Avoidance was also reported by DudokdeWit $e t a l^{\beta}$ in a study of four men enrolled in a predictive testing programme for BRCA1. The men seemed to have some difficulties with the counselling process. They were reported to miss and cancel appointments and one dropped out of the programme completely. They seemed to find it difficult to talk about the breast cancer in their family and they exhibited indications of denial. This is consistent with findings by Hallowell and Richards (personal communication) in interviews with male breast cancer sufferers from inherited breast cancer families. These men typically do not go to the GP as early in the disease as the women do. This trend among men of avoiding GP visits is well established in health psychology publications. ${ }^{16}$ Men tend to make more excuses for not seeking medical advice, stating that they are too busy or minimising symptoms (Hallowell and Richards, personal communication).

\section{Proposition 5}

Men with a symptomatic family history of breast cancer are very often excluded from family conversations about the disease.

In most of these families, conversations about breast cancer and the family history of the disease take place among the women and the men are not included in these conversations. In some cases, the men report actively avoiding such discussions. There may be sociological as well as psychological reasons for this. Possible explanations include the following. Family members may feel ill at ease discussing a disease of the sexual organs with their opposite sex family members, especially when it appears to affect one sex predominantly. Family members may feel that discussion about illness, caring for the ill, and an interest in the inheritance of physical characteristics belong to the female sex role stereotype, ${ }^{1517}{ }^{18}$ and it is thus inappropriate for the men to be involved in discussions about these subjects. Another possible contributing factor is suggested by the data here, namely the preference among many of these men for the use of avoidance strategies to cope with the breast cancer in their families. Whatever the causes of this phenomenon, it may have some implications about the way in which clinical services are offered to these families, discussed below.
CLINICAL RELEVANCE

What is the best way of dealing clinically with the risk status of daughters of potential male mutation carriers in breast cancer families? One approach would be to rely on existing communication patterns in these families. The wives of brothers of breast cancer patients are more involved with the breast cancer in the family than their husbands. However, as noted above, at the moment women with a paternal family history are under-represented in genetics clinics, so that relying on the men's sisters to involve the men's wives who would subsequently talk to their daughters may not work. Perhaps women could be encouraged to use these existing lines of communication more efficiently. This could clearly have an influence over the awareness among the daughters of potential male carriers. However, communication in these families is often not straightforward. One man in this study described what occurred when his sister (who had breast cancer) told his daughter that she was at risk of developing breast cancer. His daughter became very anxious and a "bad family scene" ensued because the man had a serious row with his sister for frightening his daughter.

Another approach would be to offer genetic counselling to the men themselves. Possible advantages of this approach (should the men take up the offer) are that knowledge of the actual risk of developing cancer themselves, and the risk and possibility of screening alternatives for their daughters, might decrease anxiety among these men. In addition, it may provide these men with the opportunity to discuss their concerns about the family history, since they appear not to engage in such discussions with their sisters and daughters. However, this may have no impact on screening behaviour among their daughters. If genetic testing can be offered to these families, it may provide the men with some sense of control. Four of the men in this study were very angry that their anxieties had been raised when no genetic test could be offered to them in Ireland. Even where genetic testing is offered, uptake is likely to be lower among the men than the women in these families.

It may be appropriate in some cases to see these men in clinic with their wives or partners. Seen as a couple, the family as a whole might benefit from their different approaches: the man's anxieties might be reduced by the information provided about actual risk and screening options for his daughter, and the woman might take on the role of communication within the family.

A family systems approach has previously been suggested to be of use in offering genetic counselling in breast cancer families. ${ }^{8} \mathrm{~A}$ family systems approach, informed by (accumulating) knowledge about differences in the coping strategies used by men and women, might be of clinical value. Adequate psychological support is important when counselling these men; discussions are likely to be less straightforward than with the women in the families and knowledge about communication patterns about genetic disease and coping strategies used in 
families will inform the counselling process. Research is continuing on communication patterns and gender issues in cancer families.

This study was conducted as an MSc dissertation, which formed part of the MSc course in Genetic Counselling at the University

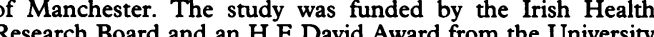
of Manchester. We thank Martin Richards and Nina Hallowell of the Centre for Family Research Cambridge University and Lauren Kerzin-Storrar, Department of Clinical Genetics, St Lauren Kerzin-Storrar, Department of Clinical Genetics, St Mary's Hospital, Manchester. We also thank the Department of all the men who took part in the study.

1 Lynch HT, Watson P, Conway TA, Lynch, JF. Natura Lynch HT, Watson P, Conway TA, Lynch, JF. Natural
history and age at onset of hereditary breast cancer. Cancer

2 Easton D. Breast cancer genes: what are the real risks? Nat Genet 1997;16:210-11

3 Miki Y, Swensen J, Shattuck-Eidens D, et al. A strong candidate for the breast and ovarian cancer gene, BRCA1. Science 1994;266:66-71.

4 Wooster R, Bignell G, Lancaster J, et al. Identification of the breast cancer susceptibility gene BRCA2. Nature 1995;378: 789-92.

5 Watson M, Murday V, Lloyd S, Ponder B, Averill D, Eeles R. Genetic testing in breast/ovarian cancer (BRCA1) families. Lancet 1996;346:583.

6 Watson M, Lloyd SM, Eeles R, et al. Psychosocial impact of testing (by linkage) for the BRCA1 breast cancer gene - an investigation of two families in the research setting. PsychoOncology 1996;5:233-9.
7 Green J, Richards M, Murton F, Statham H, Hallowell N. Family communication and genetic counselling: the case of hereditary breast and ovarian cancer. $f$ Genet Couns hereditary breast

8 DudokdeWit AC, Tibben A, Frets PG, et al. Males at risk for the BRCA1 gene, the psychological impact. PsychoOncology 1996;5:251-7.

9 Glaser BG, Strauss AL. The discovery of Grounded Theory. London: Weidenfeld \& Nicholson, 1967.

10 Pidgeon NF, Turner BA, Blockley DJ. The use of Grounded Theory for conceptual analysis in knowledge elicitation. $f$ Man-Machine Studies 1991;35:151-73.

11 Strauss A, Corbin J. Basics of qualitative research: Grounded Theory procedures and techniques. London: Sage, 1990.

12 Claus EB, Risch N, Thompson WD. Autosomal dominant inheritance of early onset breast cancer. Cancer 1994;73: 643-51.

13 Hoskins KF, Stopfer JE, Calzone KA, et al. Assessment and counselling for women with a family history of breast cancer. $\mathcal{F} A M A$ 1995;273:577-85.

14 Green J. Making sense of a family history of cancer. Paper given to the Institute of Biology National Conference, Edinburgh, 8 April 1995.

15 Richards MPR. Families, kinship and genetics. In: Marteau T, Richards MPM, eds. The troubled helix: social and psychological implications of the new human genetics. Cambridge: Cambridge University Press, 1996.

16 Stacey M. The sociology of health and healing. London: Unwin Hyman, 1988.

17 Eagley, AH. Sex differences in social behaviour: a social role interpretation. London: Laurence Erlebaum Associates, 1987.

18 Oakley A. Sex, gender and society. London: Temple Smith, 1972.

(⿸丆口 